\title{
9
}

\section{China can grow and still help prevent the tragedy of the $\mathrm{CO}_{2}$ commons}

\author{
Warwick J. McKibbin, Peter J. Wilcoxen and Wing Thye Woo
}

\section{On the road to prosperity}

China and India have finally embarked on the path of modern economic growth. China's economy has grown at an average annual rate of almost 10 per cent for the past 30 years, and India's has grown more than 8 per cent every year since 2004. Just like the experiences of post-1868 Japan and post-1960 South Korea and Taiwan, China and India are now on the trajectory of catch-up growth that will bring them in the long run to the same living standard as Western Europe, Japan and the United States. At that point, the share of global income produced by China and India will equal their share of global population (which is anticipated to be about 35 per cent).

This projected parity in living standards in the long run will represent a return to the global economic situation that persisted in the first 1,600 years of the Gregorian calendar (Table 9.1). In year zero, China and India had 58 per cent of the global population and 59 per cent of global gross domestic product (GDP); and the respective numbers in 1600 were 53 per cent and 52 per cent (despite the growing divergence in GDP per capita in Western Europe from 1500 onwards). The relatively slow growth of China and India in the past 400 years changed the situation dramatically. By 1973, China and India's share of global GDP had fallen to only 7.7 per cent although the two countries accounted for 37 per cent of the world's population. China's economic deregulation and integration into the world trade and financial systems since 1978 and India's since 1991 raised their share of world GDP to 20.6 per cent in 2003. ${ }^{1}$ Given the 


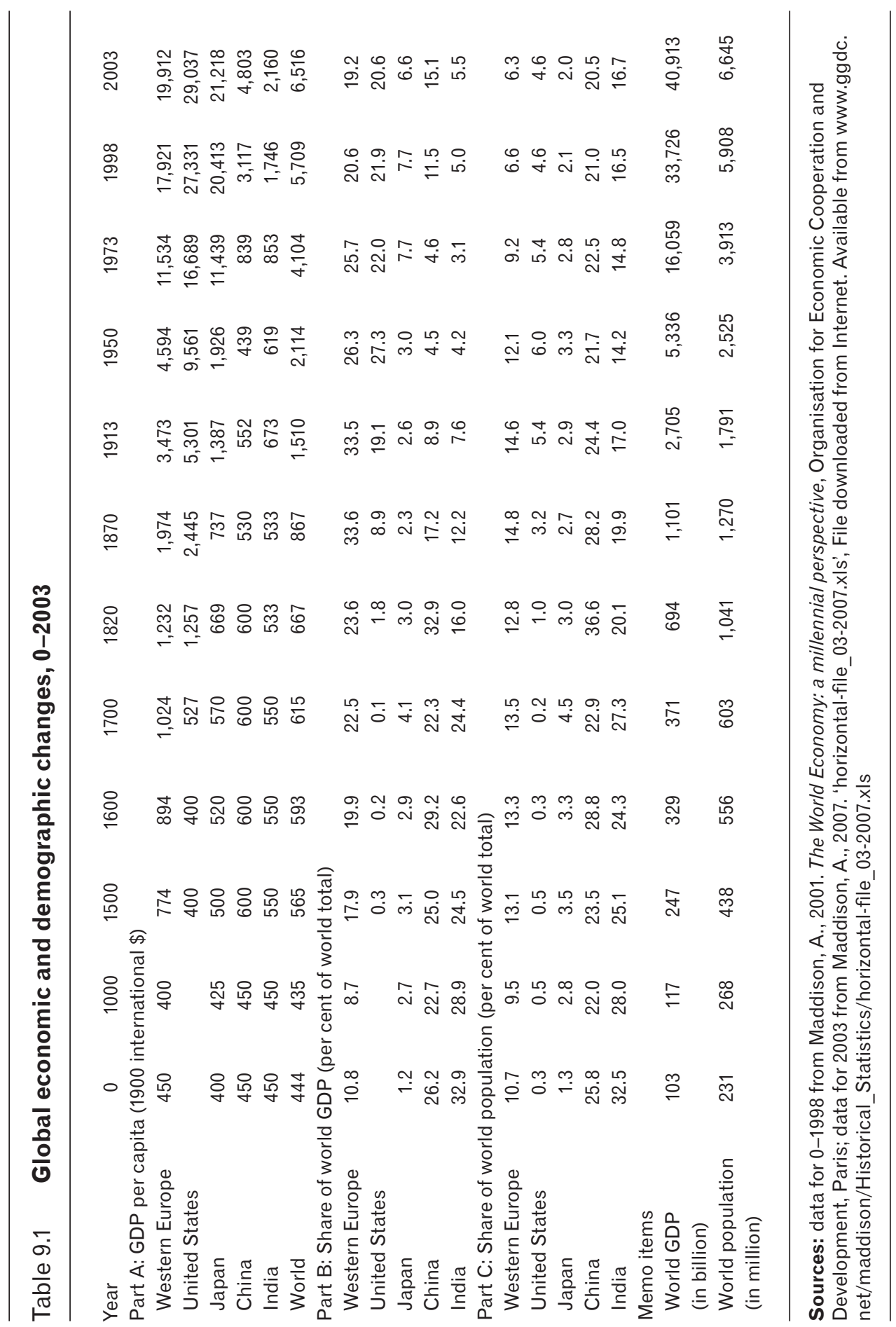


still large gap between the average income in China and Western Europe in $2003-\$ 4,803$ and $\$ 19,912$, respectively (measured in 1990 international GearyKhamis dollars) ${ }^{2}$ - continued high growth in China could continue for the next two decades.

The very likely return of China to the centre stage of the global economy has given rise to immense optimism on some fronts, and intense pessimism on a number of other fronts. Optimistic analysts have predicted that China's re-emergence as an independent growth pole will create a new web of synergistic relationships that will unleash greater global prosperity. On the other hand, pessimistic analysts have pointed out that the major new rising powers in the twentieth century came into conflict with the existing powers: Germany in World War I, the Japanese-German axis in World War II and the Soviet Union in the Cold War.

The important lesson from the history of the twentieth century is not, however, that conflict is inevitable but that rising powers and existing powers should work together to avoid past mistakes-to falsify Karl Marx's quip that 'history repeats itself, first as tragedy, second as farce'. It is really not naive to think that conflict is preventable because the most important power to rise and prevail in the twentieth century was the United States, and it has, in general, been a stabilising force in the international order. Averting the pessimistic outcome requires adherence to the multilateralist principle of the existing powers accommodating rising powers, and the latter becoming responsible stakeholders in the international system.

The dialogue between the existing and rising powers must necessarily be comprehensive because the range of global public goods that must be supplied is very broad (ranging from the maintenance of the universal postal system to the peaceful use of outer space), and the nature of some of these global public goods is highly complicated (for example, a scheme to control the emission of greenhouse gases). In this chapter, we will confine discussion to an economic issue in which the need to engage China in constructive dialogue is important for sustainable global growth. The issue is the protection of the global environmental commons by addressing China's emissions of carbon dioxide.

The chapter is organised as follows: section two makes the case that climate change could be a key obstacle for China. It shows that even under conservative assumptions, the business-as-usual growth path might cause an environmental collapse before China achieves parity in living standards with the countries in the OECD. Section three reviews the history of energy production and consumption in China, and then uses a dynamic multi-country general-equilibrium model (the G-cubed model) to project a realistic business-as-usual trajectory for carbon 
dioxide emissions. Section four proposes a novel hybrid policy as an alternative to the commonly discussed cap-and-trade mechanism to control carbon dioxide emissions. Section five employs the $\mathrm{G}$-cubed model to examine the economic consequences of the different instruments to reduce carbon dioxide generation. Section six concludes with recommendations for the form of future international climate agreements and how China can be encouraged to participate.

\section{The fallacy of composition in modern economic growth?}

We began this chapter with the optimistic projection that China and India will achieve parity in living standards with Western Europe, which leads immediately to the question of when this convergence will occur. Between 1913 and 2003, when Japan was on its catch-up growth trajectory, the annual growth rate of average income was 3.1 per cent in Japan and 1.9 per cent in Western Europe and the United States. It is possible to use this information to undertake a very crude back-of-the-envelope calculation to see what stresses might begin to emerge over time. Suppose we assume that

- Western Europe grows 1.5 per cent annually from 2003 onwards

- China and India grow 3.1 per cent annually from 2003 until reaching parity with Western Europe, and then 1.5 per cent annually.

Under these assumptions, China will achieve income parity with Western Europe by 2100 , and India will achieve parity by $2150 .^{3}$ The common GDP per capita in 2150 will be about $\$ 180,000$.

This extrapolation might fail to be realised, however, not because of political reasons, as commonly feared, but because of environmental reasons. It will not be wars that will derail the catch-up growth; rather, the growth process could prove to be unsustainable because of the fallacy of composition. Specifically, it is possible that a continual improvement in living standards might be achievable for a small subset of large countries, but not for all large countries together. A global equilibrium with a common living standard, which existed in the first millennium, might not be replicable in 2150 because the earlier situation was an agriculture-dominated equilibrium in which the average income was stagnant at $\$ 440$. In contrast, the envisaged global equilibrium will have an average income of $\$ 180,000$, which will be growing at 1.5 per cent annually.

The difference is between the vicious circle of Malthusian growth and the process of what Simon Kuznets (1966) has labelled 'modern economic growth (MEG)'. In MEG, society is urbanised, the economy is industrialised and increasingly service oriented, and human capital rivals physical capital in its contribution to economic growth. A key ingredient, so far, in this historically 
unprecedented sustained growth in prosperity has been energy from fossil fuels. The result is that the concentration of carbon dioxide in the earth's atmosphere has risen from 280 parts per million (ppm) in the pre-industrial age to 379 ppm in 2005 (IPCC 2007:37).

Under existing energy technologies, the scale of growth in China and India will be associated with a very large increase in global carbon dioxide emissions and with rapidly rising carbon dioxide concentrations. There is now a substantial literature suggesting that the increase in carbon dioxide concentrations has contributed substantially to global warming and climate change. ${ }^{4}$ According to the Intergovernmental Panel on Climate Change (IPCC 2007), climate change has

- very likely contributed to sea-level rise during the latter half of the twentieth century

- likely contributed to changes in wind patterns, affecting extra-tropical storm tracks and temperature patterns

- likely increased temperatures of extremely hot nights, cold nights and cold days

- more likely than not increased the risk of heat waves, areas affected by drought since the 1970 s and the frequency of heavy precipitation events

- led to the ocean becoming more acidic, with an average decrease in $\mathrm{pH}$ of 0.1 units. $^{5}$

There is serious concern expressed in IPCC reports that there could be severe and irreversible problems resulting from climate change. ${ }^{6}$ What is the level of the threshold carbon dioxide concentration that would unleash calamity on the world economy and human life? The truth is that we do not know. David King, the chief scientific advisor to the British government, suggested that 'we should prevent atmospheric $\mathrm{CO}_{2}$ [concentrations] going beyond 500 ppm' (Kirby 2004), ${ }^{7}$ and Michael Raupach, an Australian atmospheric scientist, advocated a limit of 550 ppm (Beer 2007). ${ }^{8}$ It has become quite common to adopt the position that the threshold carbon dioxide concentration for dangerous consequences is 560 ppm-a doubling of the pre-industrial value of $280 \mathrm{ppm}$. Of course, the possibility that the threshold is 500 ppm or even 840 ppm cannot be ruled out definitively on a priori grounds.

At the present incremental rate of $2 \mathrm{ppm}$ of atmospheric carbon dioxide annually, the 560 ppm mark would be breached by 2100 , just when China is about to reach parity in living standards with Western Europe. ${ }^{9}$ If there were indeed a catastrophic threshold of carbon dioxide concentration of $560 \mathrm{ppm}$, 
China and India could achieve income parity with Western Europe, Japan and the United States in 2150 only because the environmental collapse triggered by the growth of China and India brought down the incomes of Western Europe, Japan and the United States! This new equilibrium of income parity produced by the 'fallacy of composition' could well be characterised by global acrimony and strife.

The crucial point is that one does not have to accept the existence of a catastrophic threshold level of carbon dioxide concentration in order to conclude that unless there are future revolutionary breakthroughs in green technology or fundamental shifts in the nature of economic growth, China and India could achieve income parity with the rich countries only by creating serious global environmental problems. Clearly, China is one of the key countries that needs to be brought into the global framework with a clear commitment to take action on greenhouse gas emissions.

Figure 9.1 Comparison of projections of energy consumption in China, 1990 - 2030 (quadrillion $\left[10^{15}\right]$ BTU)
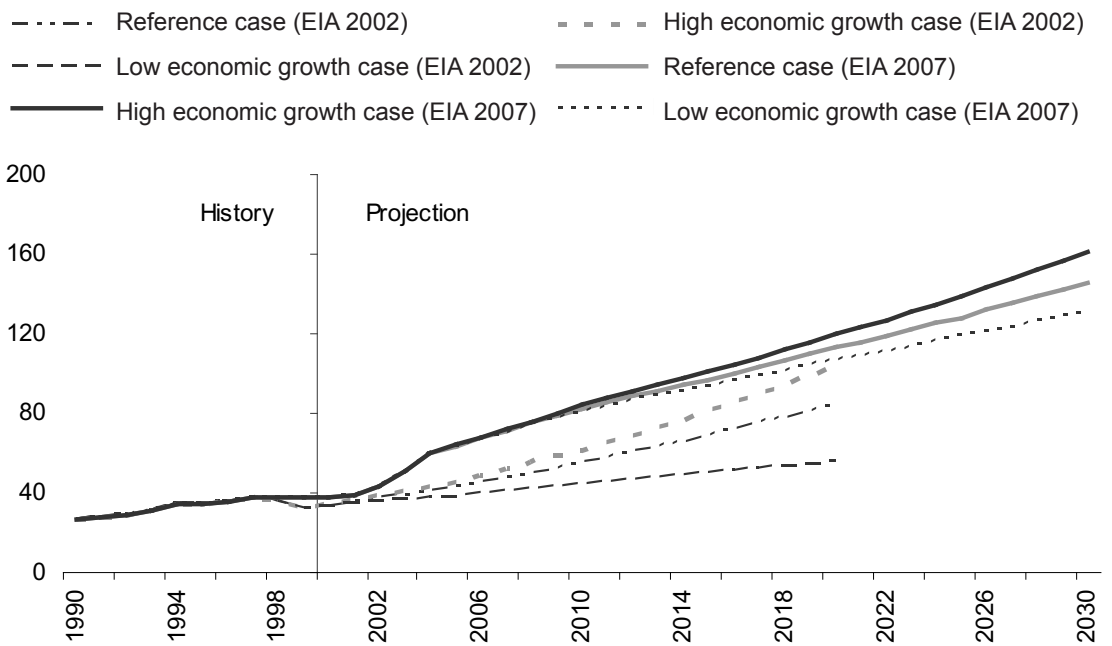

Note: The base years for projections reported in EIA 2002 and 2007 are 1999 and 2004, respectively.

Sources: Energy Information Administration / International Energy Outlook 2002 and 2007 
Moreover, it is important to bring China quickly into an international agreement because its dramatic recent rises in energy use and greenhouse gas emissions have been unanticipated by most analysts, and the potential for further upside surprises on emissions remains as China's strong growth could be more durable than anticipated. For example, the Energy Information Administration (EIA) of the US Department of Energy provides projections of carbon dioxide emissions by major countries in its annual International Energy Outlook. The EIA makes projections for Chinese energy consumption for three scenarios: high economic growth, the reference case and low economic growth.

Figure 9.1 reports projections from the 2002 International Energy Outlook (EIA 2002) and the 2007 International Energy Outlook (EIA 2007). The shocking fact is that for the future years that overlap in both reports, in every case China's projected energy consumption in the low-growth scenario in the 2007 report is above the projected energy consumption in the high-growth scenario in the 2002 report. The 2002 high-growth forecast for 2020 was 102.8 quadrillion British thermal units (BTU) and the 2007 low-growth forecast for 2020 was 106.6 quadrillion BTU. The 2002 'reference-case' forecast was 84.4 quadrillion BTU in 2020, and the 2007 reference-case forecast was 112.8 quadrillion BTU in 2020 - an upward revision of 33.6 per cent. Even more important, carbon dioxide emissions in 2005 were 50 per cent higher than the forecast made in 2002.

\section{Past and future patterns of energy use and carbon dioxide emissions in China}

China is now the second largest user of energy in the world after the United States, and the EIA (2007) projects China will become the largest by 2025 (Table 9.2), when China will consume 19.6 per cent of the world's supply of energy and the United States will consume 19 per cent. China will, however, become the world's biggest emitter of carbon dioxide earlier than 2025. In 2015, China will account for 20.7 per cent of global carbon dioxide emissions while using 17.4 per cent of global energy, and the same figures for the United States will be 19.4 per cent and 20.1 per cent, respectively. This is partly because it is anticipated that China will expand its use of fossil fuels.

The fuel composition of energy consumption in China is shown in Figure 9.2. Much of the recent rise in energy consumption took the form of an increased use of coal. Coal has been the major energy source in China throughout the period of growth since the reforms in the early 1990s. The surge in energy use since 2002 is obvious from the figure, and it results from a number of factors including rising GDP growth since 1998 (Figure 9.3) and a recent rise in the energy intensity of GDP (Figure 9.4). The shift in the energy intensity of the 


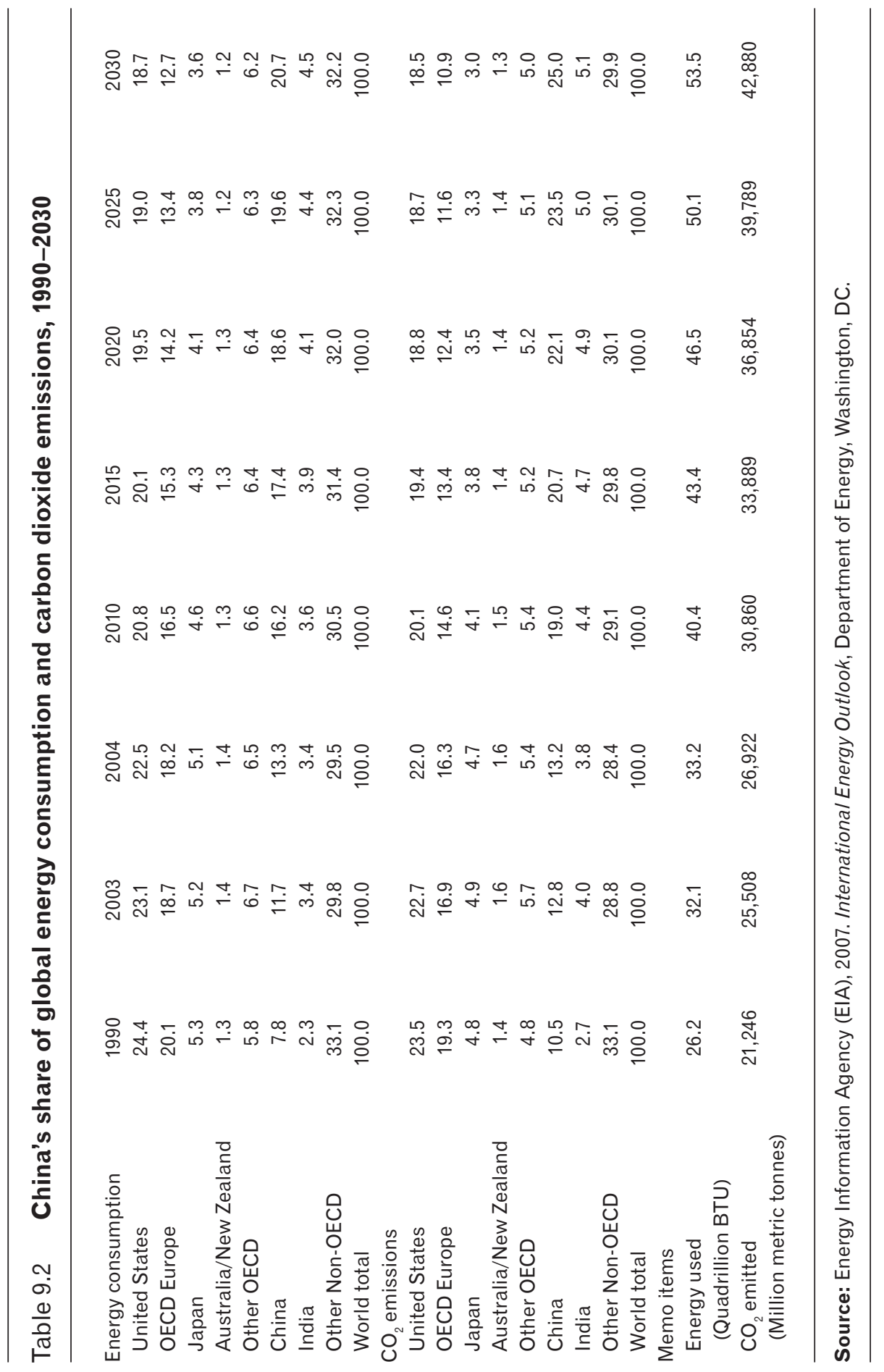


Chinese economy was due to a number of factors driving structural change, including: increased electrification, greater energy demand from manufacturing, greater energy demand by households and greater use of cement and steel as infrastructure spending rose.

Perhaps more interesting than the historical experience of Chinese energy use are future trends in energy and greenhouse gas emissions, particularly since an increasingly worrying picture of the global climate has emerged in the past half-decade. Projecting future energy use and greenhouse gas emissions in China, especially over horizons of more than a decade, is very difficult. It is tempting to construct future projections by simple extrapolation of recent trends. A somewhat more sophisticated approach is to apply the 'Kaya identity' (Kaya 1990), which decomposes emissions growth into four components: changes in emissions per unit of energy, changes in energy per unit of per capita GDP, growth of per capita GDP, and population growth. The four components are then projected separately. This is the approach taken, for example, in many of the studies cited by the IPCC (2007) and by Garnaut et al. (2008).

The Kaya identity is a useful historical decomposition but it is not an ideal forecasting framework. Each of its components is really an endogenous outcome resulting from a wide variety of individual decisions, and they cannot be

Figure 9.2 Energy consumption in China by source, 1980-2005

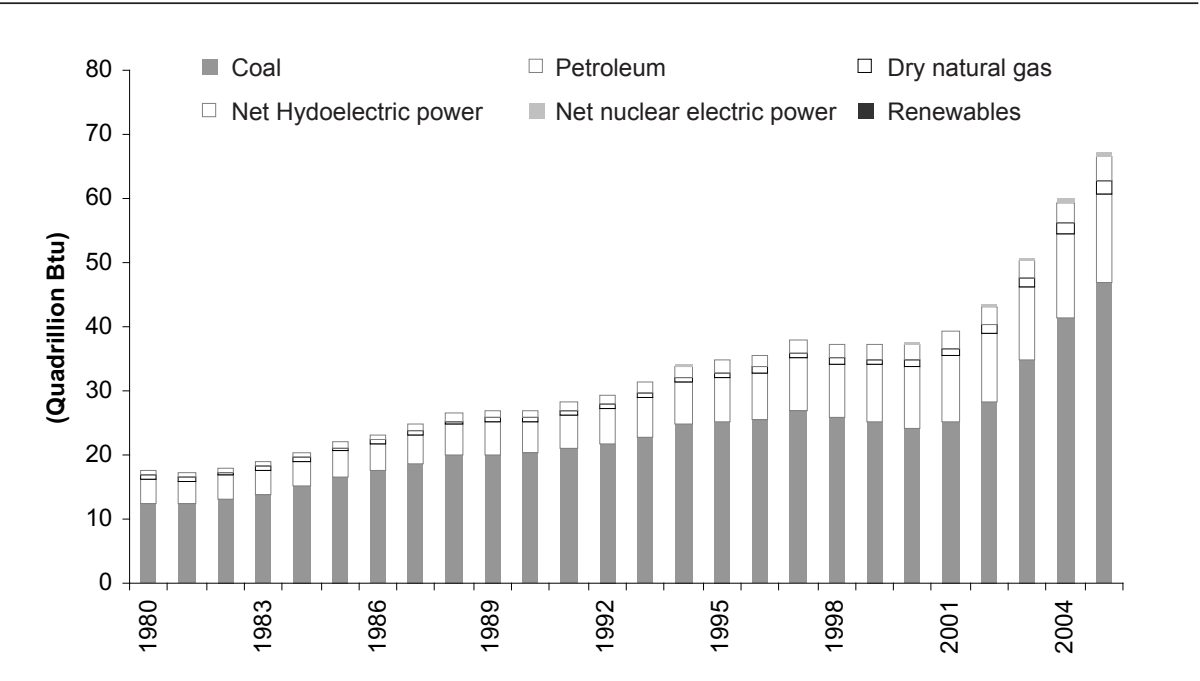

Source: Energy Information Agency (EIA), 2007. International Energy Outlook, Department of Energy, Washington, DC. 


\section{Figure 9.3 Chinese GDP growth in purchasing power parity, 1980 - 2005}

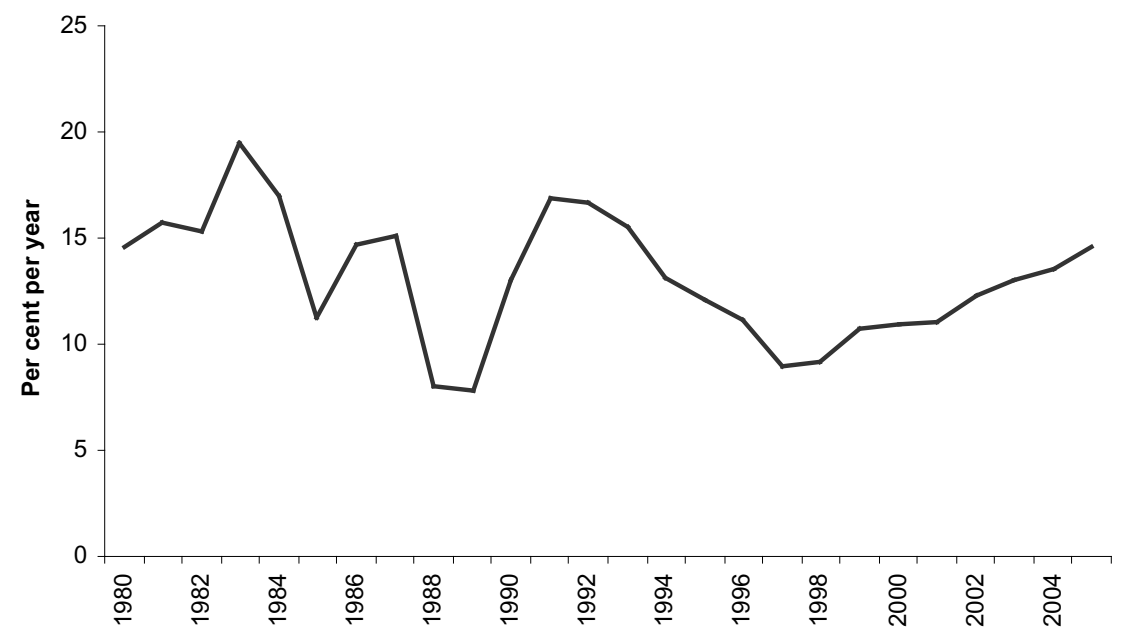

Source: International Monetary Fund (IMF), 2008. World Economic Outlook, April, International Monetary Fund, Washington, DC.

\section{Figure 9.4 Energy (1,000 BTU) per unit of GDP (purchasing power parity) $(1980=100), 1980-2005$}

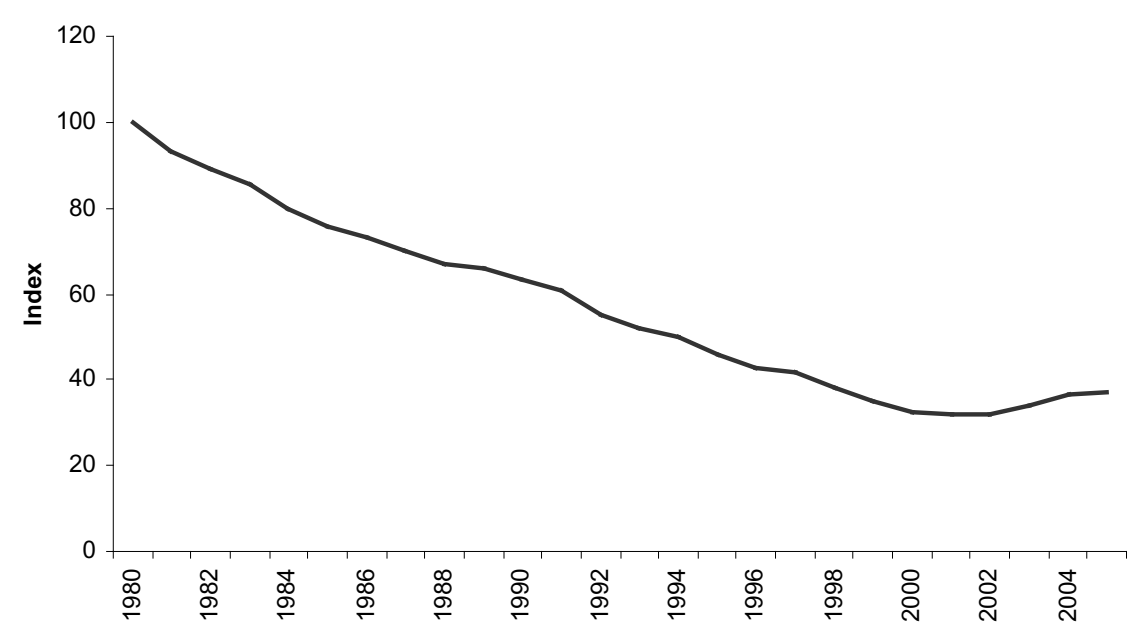

Source: Energy Information Agency (EIA), various years. International Energy Outlook, Department of Energy, Washington, DC. 
assumed to remain constant in the future. As shown by Bagnoli et al. (1996) and McKibbin et al. (2007), overall economic growth is not the only important determinant of energy use. Identifying and understanding the underlying sources of economic growth is critical, and it is particularly important to understand how the structure of an economy evolves in response to changes in energy prices.

Figure 9.5 shows EIA projections for carbon dioxide emissions by energy source in China for the reference-case scenario. It is clear that coal is the overwhelming source of carbon dioxide emissions in China-historically and in these projections. It is expected to be the major source of energy, and therefore emissions, in the foreseeable future. This is not surprising given the large quantity of low-cost coal available in China and the assumptions of unchanging relative energy prices in these projections. Over time, the share of emissions from petroleum is projected to rise with greater use of motor vehicles and other transportation. These types of projections are dependent on assumptions about the relative price of energy to other goods and the relative price of alternative energy sources.

\section{Figure 9.5 Projections of carbon dioxide emissions by fuel type in China, 1990-2030 (mega-tonnes of carbon dioxide)}

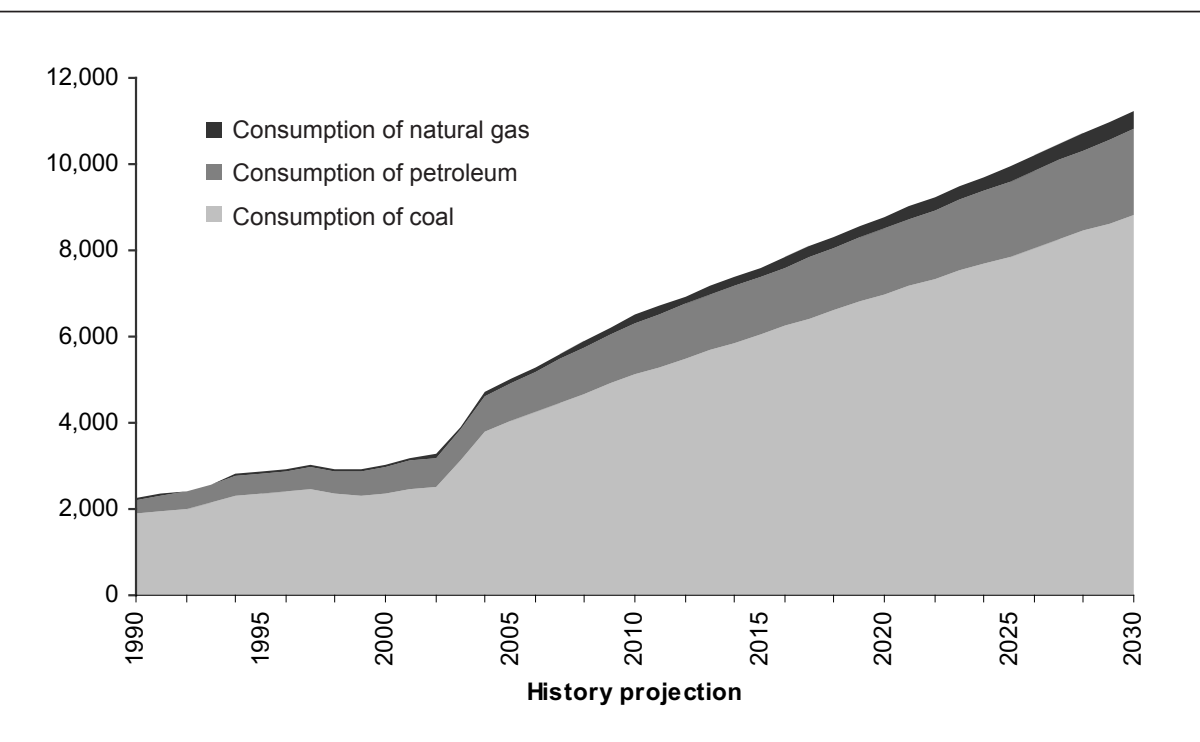

Source: Energy Information Agency (EIA), 2007. International Energy Outlook, Department of Energy, Washington, DC. 
Figure 9.6 shows the global sources of carbon dioxide from burning fossil fuels, by region, in 1990 and those projected in the 2007 International Energy Outlook (EIA 2007) for 2030. Not only is China currently an important source of carbon dioxide emissions, it is expected to grow quickly. Its absolute size, shown in Figure 9.6, and its share in global emissions (shown in Table 9.1) emphasise that China is a critical country in the debate about policies to deal with climate change.

We now present our own projections of carbon dioxide emissions from the G-cubed multi-country model (McKibbin and Wilcoxen 1998; gcubed.com). A summary of the approach is provided here but further details on the technique used in the G-cubed model can be found in McKibbin and Wilcoxen (2007). In the following discussion, the sources of economic growth are labour-augmenting technical change at the industry level and population growth. The population growth assumptions are based on the 2006 UN population projections (midscenario). In order to simplify the discussion, labour-augmenting technical change is referred to as 'productivity growth' throughout the remainder of this chapter.

In the G-cubed model, a productivity catch-up model is assumed to be the driver for productivity growth by sector and by country. The United States is assumed to be the technological leader in each sector. Other countries are allocated an initial productivity gap by sector and a rate at which this gap is

Figure 9.6 Global carbon dioxide emissions from fossil fuels, 1990 and 2030

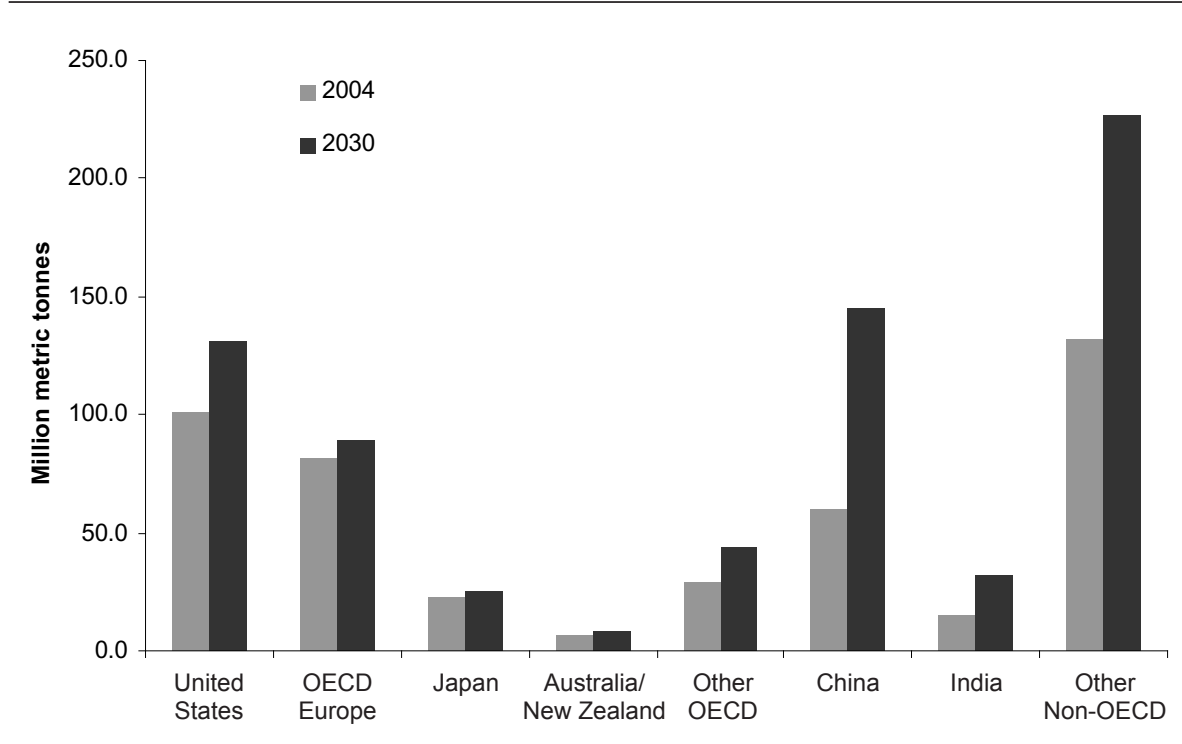


closed. For industrial countries and China, this is assumed to be a time-varying rate, which on average is 2 per cent per annum from 2006. For other developing countries, it is assumed to range between 2 per cent per annum and 1 per cent per annum, depending on the region. In this chapter, initial Chinese productivity is assumed to vary across sectors, and averages about 20 per cent of the productivity in the equivalent sector in the United States in 2002.

The results from the G-cubed model for Chinese carbon dioxide emissions are shown in Figure 9.7. This has a business-as-usual baseline as well as two other lines that will be discussed in section five below, which involve different assumptions about policy interventions. The business-as-usual projections from G-cubed are higher than the projections in EIA (2007). Carbon dioxide emissions in

- the EIA low-growth scenario rose from 6,400 mega-tonnes (Mt) in 2010 to $10,143 \mathrm{Mt}$ in 2030

- the EIA reference-case scenario rose from 6,497 Mt in 2010 to 11,239 Mt in 2030

- the EIA high-growth scenario rose from 6,615 Mt in 2010 to $12,500 \mathrm{Mt}$ in 2030

- the G-cubed model rose from 7,855 Mt in 2010 to 14,114 Mt in 2030.

The difference between the EIA's projections and those of G-cubed is reminiscent of the difference between the EIA's 2002 and 2007 projections. The higher projections by G-cubed come from it forecasting a higher economic growth rate in China than the EIA (2007) and a smaller change in the energy intensity of GDP in China (the latter being an endogenous result of the assumptions imposed for sectoral productivity growth in China). It must be stressed, however, that our G-cubed projections (like projections by others) are highly uncertain and change quite significantly if assumptions about the rate of catch-up are varied.

\section{The principles to guide reduction in carbon dioxide emissions}

There are many vexing, fundamental issues in deciding how to prevent catastrophic climate change. These issues include the following.

- There is still much about the science of climate change that we do not fully understand. Is climate change a linear or an abrupt discontinuous function of carbon dioxide concentration? ${ }^{10}$ Is there are saturation point in the absorptive capacity of the earth's sinks for atmospheric carbon dioxide?

- There are immense difficulties in computing the costs and benefits of climate change. How should we value irreversible events such as species 
extinction? How should we value the benefits to the present generation and the costs to the unborn future generations?

- There are serious challenges to designing effective implementation and oversight mechanisms for the carbon dioxide reduction process. How can national carbon dioxide caps be enforced? How can we build in incentives for mutual policing among the polluters dispersed around the world?

- The reduction of carbon dioxide emissions will only delay, not stop, the increase in carbon dioxide concentrations towards the danger level. The only long-term solution is likely to be shifting to non-fossil fuel energy. It is, however, impossible to know when these alternative fuels will be available at commercially viable costs, and at the vast scales that will ultimately be required. If the carbon dioxide reduction mechanism is designed to buy time for this development, how long will we need?

- There is unlikely to be an amicable way to distribute the burden of reducing carbon dioxide. Should the existing polluters be 'grandfathered' into the international treaty? What should be the relative burden for the rich, middle-income and poor nations? Alternatively, should the cap be based on carbon dioxide allowances per person?

The world, obviously, cannot afford to continue on the business-as-usual path until there is broad consensus about most of the above issues. Rates of carbon dioxide emissions are increasing, the tangible consequences of climate change are already evident and there is the real possibility that 'projections from climate models have been too conservative' (Gulledge 2008:56). ${ }^{11}$ The sense of urgency is real, and this is why many countries signed the Kyoto Protocol on 11 December 1997 as a pragmatic way to effect at least a temporary improvement on the business-as-usual situation. The signatories from industrial countries agreed to reduce their carbon dioxide emissions in the period 2008-12 to 95 per cent of their 1990 levels, on average (that is, 5 per cent below their 1990 emissions), and to allow the permits for carbon dioxide emissions to be tradable internationally. China was not required to undertake any reduction because it was a developing country. The United States signed the treaty but never ratified it because it exempted large developing countries, particularly China and India. Since the United States and China are the world's two largest carbon dioxide emitters, ${ }^{12}$ the Kyoto Protocol was rendered grossly inadequate as a carbon dioxide reduction mechanism. Nordhaus (2008:92) has estimated that global emissions in 2010 under the Kyoto Protocol will be only 1.5 per cent lower than under the business-as-usual outcome. 
To be effective, any carbon dioxide reduction scheme must include as many of the large emitters as possible and it should move them towards substantial long-term reductions in emissions. There are three classes of market-based mechanisms that could put the world on this agreed global carbon dioxide emissions path

- mechanisms that do not specify the carbon dioxide emissions path for each country: for example, a global carbon tax

- mechanisms that specify an immediately binding carbon dioxide emissions path for each country: for example, a domestic cap-and-trade scheme or an international cap-and-trade scheme

- mechanisms that specify a carbon dioxide emissions path that is not immediately binding: for example, a domestic carbon tax or the McKibbin-Wilcoxen hybrid (MWH) approach.

In practice, actual emissions are unlikely to hit target emissions at every point in time. We label the quantity target 'immediately binding' if the emissions above the target are explicitly penalised. The quantity target is labelled 'not immediately binding' when the above-target emissions pay the same carbon tax as the below-target emissions, and the carbon tax is later adjusted to bring anticipated emissions to the target path. Naturally, the global and national target paths, and the level of international and domestic carbon taxes are modified over time to take into account how close the actual emissions have been to target emissions, revelations in abatement costs and developments (and anticipated developments) in areas such as technology.

\section{The global carbon tax}

Given a desired time path of global carbon dioxide emissions, it could be possible to identify a time-varying common carbon tax that would motivate the private sector in each country to hold collective carbon dioxide emissions to the target amount in the absence of unexpected developments. A global carbon tax would have to be revised at fixed periods in light of its performance, improvements in technology, advances in scientific knowledge and new information and ideas. A global carbon tax has the virtue of not distorting the comparative advantage of the different countries.

Since much of the increase in atmospheric carbon dioxide concentrations since the Industrial Revolution has been due to industrialised countries, perhaps developing countries could be exempted from the global carbon tax for a period or until they have reached a certain level of income. 
The domestic carbon tax

A carbon tax could also be applied at the domestic level. Given a time profile of desired carbon dioxide emissions for a country, it would be possible to identify the carbon tax required to achieve this. This approach is, however, likely to be inefficient in the global sense because it will not guarantee that the marginal cost of emissions reductions will be the same across countries. The probable outcome would be a distortion of comparative advantage. Again, developing countries might be exempted temporarily from having to impose this domestic carbon tax.

\section{Domestic cap and trade}

A country could issue emissions permits to match a national target emissions path. The permits could be given free to existing carbon dioxide emitters or auctioned to the general public, and would be tradable within the country but not across borders. This approach, like the domestic carbon tax, is unlikely to produce a globally efficient pattern of abatement. Developing countries might be given ceilings on carbon dioxide emissions that are binding only when they attain a particular income level.

\section{International cap and trade}

An international treaty that establishes a global carbon dioxide emissions path and allocates carbon dioxide emissions among countries could also allocate internationally tradable emissions permits to those countries; the Kyoto Protocol falls under this category. Developing countries could be given more permits than they would need for their current emissions, and they could then sell the excess and use the revenue to accelerate development and buy green technology. This approach would equate the costs of abatement at the margin and would not distort comparative advantage.

\section{The McKibbin-Wilcoxen hybrid (MWH) approach}

McKibbin and Wilcoxen (2002a, 2002b) have proposed a hybrid approach that combines

- an internationally determined path for emissions reductions for each country, which is translated into a limited supply of long-term national permits

- sales of annual national permits (in order to accommodate deviations from a national path) sold at a price that is determined by international negotiations: say, every five years. 
Both types of permits would be valid only in the country of issue: there would be no trade across borders. ${ }^{13}$ Every year, firms would be required to hold a portfolio of permits equal to the amount of carbon they emit. ${ }^{14}$ The portfolio could include any mix of long-term and annual permits. The long-term permits could be owned outright by firms, or they could be leased from other permit owners. Except for the case of developing countries, which we will discuss in detail later, the amount of long-term permits for each country would intentionally be set lower than the anticipated amount of emissions (for example, set below the target emissions path). If the target turns out to be sufficiently tight, there will be demand for the annual permits, which will impose an internationally fixed upper bound on the short-term price of carbon emissions.

Each country would manage its own domestic hybrid policy using its own existing legal system and financial and regulatory institutions. There would be no need for complex international trading rules, for the creation of a powerful new international institution or for participating governments to cede a significant degree of sovereignty to an outside authority. The international dimension of the MWH consists of two actions: 1) setting a notional (or 'aspirational') greenhouse gas emissions trajectory for each country; and 2) harmonising the price of annual permits across participating countries. ${ }^{15}$

The number of long-term permits would be guided by the international negotiations over the target emissions path for the country. For example, the international treaty establishing the $\mathrm{MWH}$ mechanism could suggest that signatories distribute no more long-term permits than their allotments under the Kyoto Protocol. The number of long-term permits would be set when a country joined the scheme, but the country's government would have considerable flexibility in how the permits were used. A government that wished to tackle climate change more aggressively could choose to distribute few long-term permits; ${ }^{16}$ and a government that preferred a carbon tax could distribute no long-term permits at all. ${ }^{17}$ The treaty would not need to specify rigid allocations of long-term permits because emissions would generally be controlled at the margin by the price of annual permits. The number of long-term permits affects only the distribution of permit revenue between the private sector and the government; it does not affect the country's total emissions. Distributing a small number of long-term permits means the government will earn a lot of revenue from annual permit sales, but it might also lead to significant political opposition. Distributing a larger number means less government revenue but the permits would be very valuable to the private sector and permit owners could be expected to form a powerful lobby in support of the policy. In either case, one country's decision has little effect on other signatories. 
Long-term permits

A 100 -year permit would be akin to a book of 100 coupons, with each coupon corresponding to a particular year and stating the amount of greenhouse gas emissions the holder is entitled to emit. In line with a declining level of target emissions, the coupon for each year would allow a smaller amount of greenhouse gas emissions than the previous year. Once distributed, the long-term permits could be traded among firms, or bought and retired by environmental groups. The permits would be very valuable because: 1) there would be fewer available than needed for current emissions; and 2) each permit would allow annual emissions over a long period. As a consequence, the owners of long-term permits would form a private-sector interest group that would greatly enhance the long-term credibility of the policy: permit owners would have a clear financial interest in keeping the policy in place.

When initially distributed, the long-term permits could be given away, auctioned or distributed in any other way the government of the country saw fit. One option would be to distribute them for free to industry in proportion to each firm's historical fuel use-for example, a firm might receive permits equal to 90 per cent of its 1990 carbon emissions. Such an approach would be relatively transparent and would limit the incentives for lobbying by firms. Although the allocation would be based on historical emissions, the tradability of the permits would mean that they were not tied in any way to the original recipient or any particular plant, and hence would not create differences in marginal costs across firms or plants. Moreover, the existence of annual permits limits the ability of incumbent firms to create entry barriers by keeping their long-term permits off the market: entrants could simply buy annual permits. Incumbent firms would benefit financially from the initial distribution of permits, but unless they were previously liquidity constrained, they would not be able to use their gains to reduce competition. ${ }^{18}$

Another alternative would be to auction the permits. Auctioned permits would be exactly like a carbon tax except that the industry would have to pay the entire present value of all future carbon taxes up front. As the number of long-term permits was intentionally kept below the target path of emissions, at least a few annual permits would be sold in every year. The price of a permit during the auction would be bid up to the present value of a sequence of annual permit purchases. 


\section{Annual permits}

The government would sell annual permits for an internationally agreed price-say, for $\$ 20$ per tonne of carbon. There would be no restriction on the number of annual permits sold, but each permit would be good only in the year it was issued. Annual permits give the policy the advantages of an emissions tax: they provide clear financial incentives for emissions reductions but do not require governments to agree to achieve any particular emissions target regardless of cost. The existence of the annual permits introduces a degree of flexibility in the target. Over time, the global carbon price would be readjusted if either the global target were not being met as well as desired or if the global target were changed because of new information about climate science or marginal abatement costs.

\section{Treatment of developing countries}

To be effective in the long run, the agreement will eventually need to include all countries with significant greenhouse gas emissions. It is unlikely, however, that all countries will choose to participate at the beginning. Developing countries, for example, have repeatedly pointed out that industrialised countries are overwhelmingly responsible for current greenhouse gas emissions, and that those countries should therefore take the lead in reducing emissions. As a result, an international climate policy will need to cope with gradual accessions taking place over many years. Its design, in other words, must be suitable for use by a small group of initial participants, a large group of participants many years in the future and all levels in between. One important role for the treaty's long-term permit guidelines would be to distinguish between industrialised and developing countries. For example, a country such as China would be allowed to distribute more long-term permits than needed for its current carbon emissions. In that case, it would be committing itself to slowing carbon emissions in the future, but would not need to reduce its emissions right away. As the country grows, its emissions will approach the number of long-term permits. The market price of long-term permits would gradually rise, and fuel users would face increasing incentives to reduce the growth of emissions. Once the long-term target becomes a constraint, annual permits would begin to be sold and would smooth out the evolution of annual carbon costs.

A generous allotment of long-term permits would reduce the disincentives to join faced by developing countries, but that alone might not be enough to induce widespread participation. If stronger incentives were needed, it would 
be possible to augment the treaty with a system of foreign-aid payments or with programs for technology transfer to participating developing countries.

\section{The firewall of separate markets under MWH}

Because the permit markets under this policy are separate between countries, shocks to one permit market do not propagate to others: for example, accession by a new participant has no effect on the permit markets operating in other countries. ${ }^{19}$ Likewise, the collapse of one or more national permit systems would be unfortunate in terms of emissions control, but it would not cause permit markets in other countries to collapse as well. In contrast, under the Kyoto Proto-col, shocks in one country-ineffective enforcement or withdrawal from the agreement, for example-would cause changes in permit prices around the world. For permit owners and permit users, investments in emissions reductions would be more risky under the Kyoto Protocol than other systems.

Compartmentalisation is especially important for a climate change agreement because of the uncertainties surrounding climate change: the agreement must survive through intervals in which warming seems to be proceeding more slowly than expected, which could create political pressure to abandon the agreement on the grounds that it is not necessary. Such intervals could arise because of random fluctuations in global temperatures from year to year, or because the policy is succeeding in reducing the problem. The latter point is worth emphasising: if a climate regime is successful at reducing warming and preventing significant damage, it will be easy for complacency to arise: many people might interpret the absence of disasters to mean that the risks of climate change were overstated.

Another advantage of multiple national permit markets, rather than a single international one, is that the incentives for enforcement are stronger. Individual governments would have little incentive to monitor and enforce an international market within their borders - and it is easy to see why: monitoring polluters is expensive, and punishing violators imposes costs on domestic residents in exchange for benefits that accrue largely to foreigners. There would be a strong temptation for governments to look the other way when firms exceeded their emissions permits. For a treaty based on a single international market to be effective, therefore, it will need to include a strong international mechanism for monitoring compliance and penalising violations. National permit markets reduce the problem substantially because monitoring and enforcement become a matter of enforcing the property rights of a group of domestic residents-the owners of long-term permits-in domestic markets. 


\section{Incentives for investments in carbon dioxide reduction under $\mathrm{MWH}$}

Some commentators argue that the MWH mechanism is more complex than an emissions tax or conventional permit system, but it is more likely to encourage private-sector investment in capital and research that will be needed to address climate change. To see why, consider the incentives faced by a firm after the policy has been established. Suppose the firm has the opportunity to invest in a new production process that will reduce its carbon emissions by 1 tonne every year. If the firm is currently covering that tonne by buying annual permits, the new process will save it $\$ 20$ per annum. If the firm can borrow at a 5 per cent real rate of interest, it will be profitable to adopt the process if the cost of the innovation is $\$ 400$ or less. For example, if the cost of adoption were $\$ 300$, the firm would be able to avoid buying a $\$ 20$ annual permit every year for an interest cost of only $\$ 15$; adopting the process, in other words, would eliminate 1 tonne of emissions and raise profits by $\$ 5$ per annum.

Firms owning long-term permits would face similar incentives to reduce emissions because doing so would allow them to sell their permits. Suppose a firm having exactly the number of long-term permits needed to cover its emissions faced the investment decision in the example above. Although the firm does not need to buy annual permits, the fact that it could sell or lease unneeded long-term permits provides it with a strong incentive to adopt the new process. To keep the calculation simple, suppose that the permits are perpetual and allow 1 tonne of emissions per annum. At a cost of adoption of $\$ 300$, the firm could earn an extra $\$ 5$ per annum by borrowing money to adopt the process, paying an interest cost of $\$ 15$ per annum, and leasing the permit it would no longer need for $\$ 20$ per annum.

The investment incentive created by $\mathrm{MWH}$ rises in proportion to the annual permit fee as long as the fee is low enough to be binding - that is, low enough that at least a few annual permits are sold. For example, raising the fee from $\$ 20$ to $\$ 30$ raises the investment incentive from $\$ 400$ to $\$ 600$.

The upper limit on incentives created by the annual fee is the market-clearing rental price of a long-term permit in a pure tradable permit system. Above that price, there would be enough long-term permits in circulation to satisfy demand and no annual permits would be sold. For example, if long-term permits would rent for $\$ 90$ a year under a pure permit system, the maximum price of an annual permit under the hybrid model would be $\$ 90$.

The critical importance of credibility becomes apparent when considering what would happen to these incentives if firms were not sure the policy was going to remain in force. If the policy were to lapse at some point in the future, emissions permits would no longer be needed. At that point, any investments 
made by a firm to reduce its emissions would no longer earn a return. The effect of uncertainty about the policy's prospects is therefore to make the investments it seeks to encourage substantially more risky.

Since the incentives created by the policy increase with the price of an annual permit, a government might try to compensate for low credibility by imposing higher annual fees. For example, suppose a government would like a climate policy to generate a $\$ 400$ incentive for investment but firms believe that there is a 10 per cent chance the policy will be abandoned each year. For the policy to generate the desired incentive, the annual permit price would have to be $\$ 60$ rather than $\$ 20$. That is, the stringency of the policy (as measured by the annual permit fee) must triple in order to offset the two-thirds decline in the incentives arising from the policy's lack of credibility. In practice, the situation is probably even worse. Increasing the policy's stringency is likely to reduce its credibility further, requiring even larger increases in the annual fee. For example, suppose that investors believe that the probability the government will abandon the policy rises by 1 per cent for each $\$ 20$ increase in the annual fee. In that case, maintaining a $\$ 400$ investment incentive would require an annual fee of $\$ 70$ rather than $\$ 60$, which would be accompanied by an increase in the perceived likelihood of the policy being abandoned from 10 per cent to 12.5 per cent.

The general lesson is that a low-cost but highly certain policy generates the same incentives for action as a policy that is much more expensive but less certain. A hybrid policy with a modest annual permit price would generate larger investment incentives than a more draconian, but less credible, emissions target imposed by a more conventional system of targets and timetables. The $\mathrm{MWH}$ proposal is more credible than a carbon tax because it builds a political constituency with a large financial stake in preventing backsliding by future governments. It is therefore likely to provide more incentive to the private sector to make investments to reduce greenhouse gas emissions.

\section{Coping with new information}

Over time, more information will become available about climate change, its effects and about the costs of reducing emissions. If it becomes clear that emissions should be reduced more aggressively, the price of annual permits can be raised. The political prospects for an increase would be helped by the fact that raising the price of annual permits would produce a windfall gain for owners of long-term permits, since the market value of long-term permit prices would rise as well. ${ }^{20}$

If new information indicates that emissions should drop below the number allowed by long-term permits, raising the price of annual permits would need 
to be augmented by a reduction in the stock of long-term permits. One option would be for each government to buy and retire some of the long-term permits it issued. Other approaches would be possible as well: for example, accelerating the expiration date of the permits.

\section{Comparing methods for reducing China's carbon dioxide emissions}

Three market-based mechanisms

The Clean Development Mechanism (CDM) of the Kyoto Protocol allows industrialised countries to use credits for emissions-reducing actions taken in China to help meet their obligations under the protocol. This approach cannot be scaled up sufficiently to have the required effect of significantly reducing China's carbon emissions because it is project based and has proven very complex and costly to administer.

In this section, we show some results for alternative policy regimes and discuss what they imply for emissions and economic growth in China. Figure 9.7 contains various paths of greenhouse gas emissions from energy use in China under three different policy regimes

- a domestic carbon tax

- an international cap-and-trade scheme

- the MWH approach.

The business-as-usual line in Figure 9.7 is the projection of Chinese emissions from energy use from the $\mathrm{G}$-cubed model under the assumptions already discussed above.

In order to compare the key aspects of the three policy regimes, we assume that all countries take on the emissions reduction path that is contained in the recent World Economic Outlook of the International Monetary Fund (IMF 2008). Emissions in each country, and for the world as a whole, rise along the business-as-usual path for a number of years, gradually peaking in 2028, falling back to 90 per cent of the 2002 emissions level about 2050 and then dropping to 40 per cent of the 2002 level by 2100 . Along this business-as-usual trajectory, China and other developing countries would take on the same commitment as industrial countries but initially with a more gradual reduction target. ${ }^{21}$

In the first policy option, labelled 'Country target' in Figure 9.7, China reaches its target by implementing a domestic carbon tax. All other countries are assumed to follow a similar strategy and achieve their targets through domestic actions only. This country-by-country targeting achieves a common global outcome but with a wide variety of costs across countries. 


\section{Figure 9.7 China's carbon dioxide emissions from energy, 2008 - 2050}

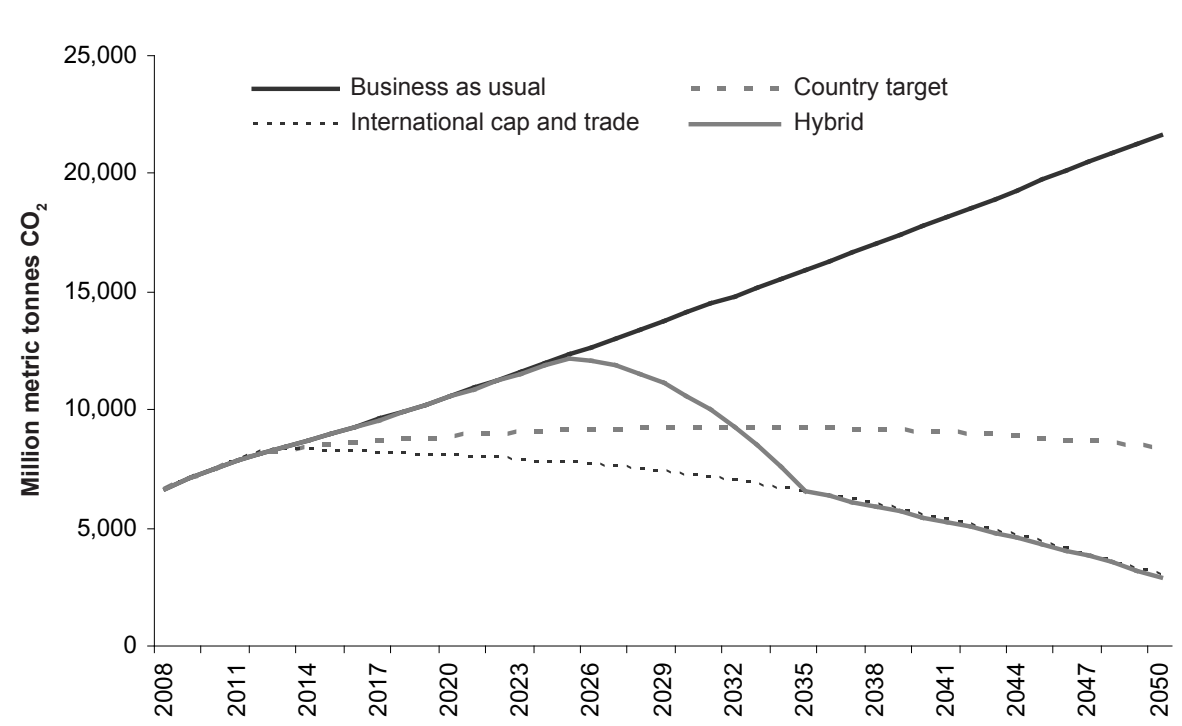

Source: G-cubed model in McKibbin, W. and Wilcoxen, P., 2008. Building on Kyoto: towards a realistic climate change agreement, Paper presented to the Brookings Institution High-Level Workshop on Climate Change, Tokyo, 30 May.

\section{Figure 9.8 China's GDP change from emissions reduction, 2008 - 2050}

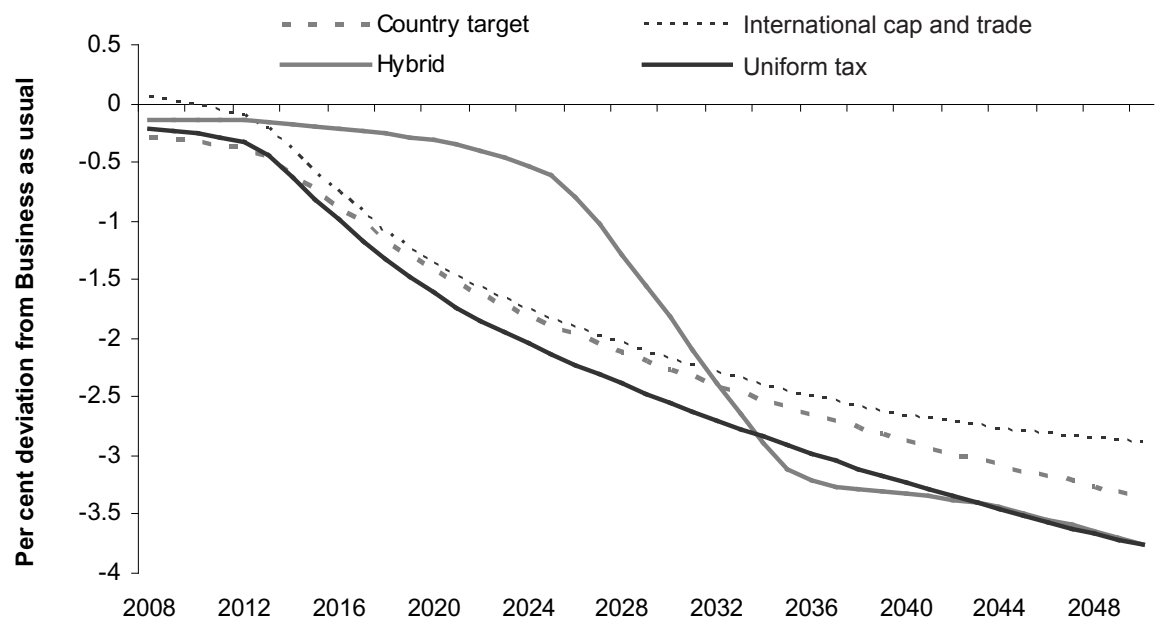

Source: G-cubed model in McKibbin, W. and Wilcoxen, P., 2008. Building on Kyoto: towards a realistic climate change agreement, Paper presented to the Brookings Institution High-Level Workshop on Climate Change, Tokyo, 30 May. 
The results indicated by the 'International cap and trade' (triangles) line in Figure 9.7 are the emissions outcomes when China is given a permit allocation based on its target emissions and is then allowed to buy or sell emissions permits on international markets. China can therefore change its emissions outcome by selling permits at the world price (which is common to all countries). In the G-cubed model, under this allocation of permits, China has among the lowest marginal abatement costs in the world-that is, it is much cheaper to reduce a unit of carbon in China than in most other countries, reflecting the energy infrastructure and sources of emissions in China. The outcome is that emissions fall more quickly in China as China cuts its emissions domestically to sell permits abroad. Eventually, the marginal cost of abatement in China rises enough to reach equilibrium with the rest of the world.

The third policy option shown in Figure 9.7 is the MWH approach, in which China is allocated an amount of long-term permits equal to twice its 2008 emissions (which is more than the real amount of emissions in the first few years of its accession to the international climate treaty) but declining over time at the same rate as other countries. ${ }^{22}$ These permits cannot be used outside China and therefore do not directly affect emissions in other countries. In this case, China's short-term carbon price is zero for a number of years because there are more permits available than needed, and emissions in China continue to rise along the business-as-usual path. When China grows enough to reach its emissions constraint, it starts to sell annual permits at the price stipulated by international agreement. Eventually, the carbon emissions path begins to fall until it reaches the emissions outcome under the international cap-andtrade system. This is not surprising since the uniform price under the MWH is designed to be almost the same as the price that would be delivered under the cap-and-trade policy. ${ }^{23}$ The results are the same because the model is run under conditions of complete certainty about future events. With uncertainty, it would be necessary to refine the carbon price iteratively over time to try to reach the desired global target in a 'learning-by-doing' fashion. Under the cap-and-trade system, however, the target would be reached but at the cost of potentially very high volatility in carbon prices, and therefore economic costs.

Figure 9.8 shows the GDP outcome for China under the three different policies. The results are expressed as a percentage deviation from the businessas-usual path. Under the 'country target' and 'cap-and-trade' regimes, GDP begins to fall from the beginning of the regime in 2013. By 2025, the GDP loss to China from the carbon policy is about 1.8 per cent per annum. The international cap-and-trade policy leads to slightly lower GDP loss than the no-trading case because China is able to sell permits to raise income, which slightly offsets the 
GDP loss for deeper cuts. The MWH model delays the significant GDP losses until China reaches the binding permit constraint, which begins about 2028.

\section{Advanced technology diffusion}

Another policy approach that is often advocated as a means of enhancing emissions reductions world-wide is the deployment of advanced energy technology in China. In this section, we present some results from McKibbin and Wilcoxen (2008) in which this policy is explored. The business-as-usual path discussed above is based on the assumption that energy technologies in each economy gradually improve at rates similar to those seen in recent historical data. Many policies now under discussion are, however, explicitly intended to accelerate the development and deployment of advanced technologies that would reduce greenhouse gas emissions. Some of these technologies, such as the integrated gasification combined cycle (IGCC) process to generate electricity from coal, reduce carbon dioxide emissions by substantially improving the efficiency of fossil-fuel combustion. Other technologies, such as carbon capture and sequestration, would reduce emissions by removing carbon dioxide from the exhaust stream after combustion. Yet other technologies, such as hybrid engines or carbon-fibre components for automobiles, would reduce emissions by lowering the fuel required per unit of service demanded (vehicle kilometres travelled, for example). Finally, advanced technology for non-fossil fuel sources of electricity, including nuclear power and renewable energy, would reduce carbon dioxide emissions by shifting the overall fuel mix. In this section, we examine the potential for accelerated deployment of advanced technology to reduce carbon dioxide emissions associated with electric power generation.

Since improved technology will allow more electricity to be produced from any given input of fossil fuel, we represent advanced technologies in the model via fuel-augmenting technical change. In essence, this approach captures the fact that new technology allows the same outcomes (output produced, distance travelled, and so on) to be produced with less physical energy. Factoraugmenting technical change introduces a distinction between physical inputs of energy (kilowatt hours, for example) and the effective value of those inputs to energy users. For example, increasing the efficiency of a coal-fired power plant from 41 per cent to 49 per cent using ultra-supercritical boiler technology would allow 19.5 per cent more electricity to be produced from a given amount of coal (an 8 per cent gain on a base of 41 per cent). In effect, the technology allows a new plant using 1 tonne of coal to produce the same amount of electricity that would have required 1.195 tonnes of coal in an older plant. The technology, in effect, serves to augment the physical fuel used. 
Because the G-cubed model aggregates all electric power technologies into a single electric sector in each country, shifts of the fuel mix away from fossil fuels towards nuclear and renewable energy can also be modelled as fossil fuel-augmenting technical change. For example, a country increasing the share of non-fossil fuel generation in its fuel mix from 40 per cent to 55 per cent, and hence reducing its fossil fuel share from 60 per cent to 45 per cent, is effectively generating 33 per cent more electricity for any given input of fossil fuel.

Using industry projections of the rate of diffusion of a range of innovations in electricity generation between 2008 and 2030, we produced the augmentation factors shown in Table 9.3. The values shown include both effects mentioned above: improvements in the efficiency of fossil-fuel combustion, and shifts in the fuel mix away from fossil fuels. By 2030, for example, the 1.66 shown for Japan indicates that advanced technology and fuel switching will mean that the ratio of total electricity produced to fossil-fuel input will be 1.66 times that ratio today. We assume that technology and fuel switching continue beyond 2030 , although at a diminishing rate. By 2045, for example, the augmentation factor for Japan increases to 2.09. The augmentation factors vary considerably by country. Improvements are very limited in developing countries other than China and India: the 2030 augmentation factor is only 1.13. India's augmentation factors are quite high, reflecting the fact that India currently relies heavily on coal burned in boilers with very low efficiency. Better technology therefore improves India's performance considerably. In contrast, Europe's augmentation factors are relatively low: it currently relies least on fossil fuels of all of the regions, and its current technology is relatively efficient. It therefore has less room for improvement.

Figure 9.9 shows the effect of the advanced-technology scenario on carbon emissions in China. For comparison, the business-as-usual results are shown as well. The business-as-usual trajectories are indicated with diamonds and the advanced-technology trajectories are indicated with triangles and labelled 'high innovation'. By 2050, emissions are lowered by $500 \mathrm{Mt}$ per annum. This is a significant reduction from focusing only on electricity generation, but interestingly it is not as large as might be expected given the substitution we have assumed. This result is seen because in a rapidly growing economy such as China, the introduction of enhanced technology results in greater wealth and this higher wealth is spent partly on greater energy consumption. When we reduce the amount of carbon per unit of electricity, therefore, we also raise the amount of electricity used. This rebound effect of technological deployment on income growth is sufficient in China to partly offset the reduction in emissions from the new technology. This suggests that a combination of policies to deploy 


\section{Table 9.3 Fossil-fuel augmentation factors i.e. productivity in} electricity generation relative to business-as-usual

$\begin{array}{lll}\text { Region } & 2030 & 2045 \\ \text { United States } & 1.67 & 2.1 \\ \text { Japan } & 1.66 & 2.09 \\ \text { Australia } & 1.73 & 2.19 \\ \text { Europe } & 1.49 & 1.8 \\ \text { Rest of OECD } & 1.67 & 2.09 \\ \text { China } & 1.67 & 2.1 \\ \text { India } & 1.8 & 2.31 \\ \text { Other developing countries } & 1.13 & 1.22 \\ \text { Former Soviet Union } & 1.71 & 2.16 \\ \text { OPEC } & 1.22 & 1.35\end{array}$

Note: Each number represents the ratio of electricity per unit of fossil fuel consumed in the advanced technology simulation to electricity per unit of fossil fuel consumed in the businessas-usual simulation.

\section{Figure 9.9 China's carbon dioxide emissions from energy under alternative technology assumptions, $2008-2050$}

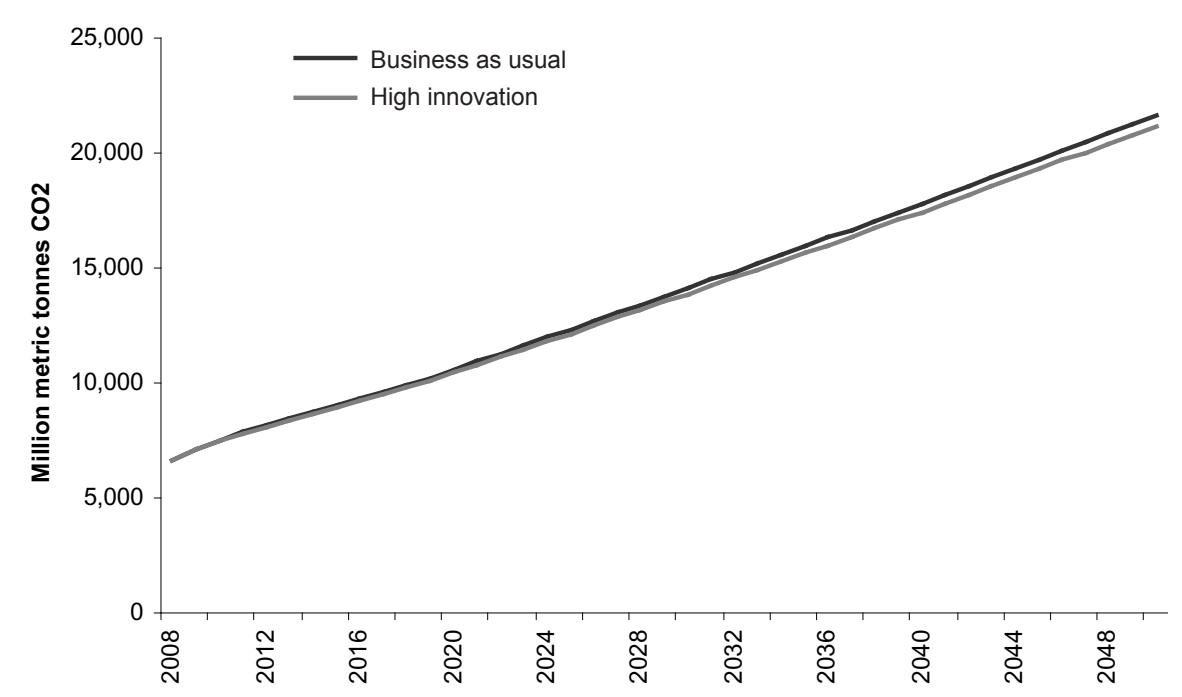

Source: G-cubed model in McKibbin, W. and Wilcoxen, P., 2008. Building on Kyoto: towards a realistic climate change agreement, Paper presented to the Brookings Institution High-Level Workshop on Climate Change, Tokyo, 30 May 2008. 
technology as well as to price carbon to encourage substitution away from carbon-intensive inputs is required in a comprehensive approach to tackle the emission of greenhouse gases.

Future research will explore the interaction of alternative technology policies and the cost of carbon abatement under the MWH policy. Combining these approaches offers a potentially important way forward in cementing a global agreement based on economic incentives and technological innovation.

\section{Conclusions}

This chapter has summarised recent developments in energy use and carbon dioxide emissions in China. The increase in emissions since 2002 has taken most analysts by surprise and is a significant concern for global policymakers attempting to deal with climate change. As shown in McKibbin and Wilcoxen (2002a), unexpected developments cause the different market-based carbon dioxide reduction mechanisms to create vastly different costs. The international carbon tax and the MWH approach are more economically efficient responses to uncertainty than the cap-and-trade of the Kyoto Protocol.

Because it is very difficult to forecast future energy and emissions paths, concerns about uncertainty could delay or prevent accession by countries (especially developing countries) to a global climate agreement based on rigid targets and timetables. The recent experience of energy use and carbon emissions in China supports the arguments in McKibbin and Wilcoxen (2008) that uncertainty about the economic costs of undertaking binding emission targets is an important problem for a rapidly developing country such as China.

As an alternative, we have outlined the MWH approach, a set of internationally agreed actions that are based on long-term emissions targets and include an explicit compliance mechanism (annual permits) that allows the constraint to be exceeded at a stipulated international price. This approach would reduce emissions but without requiring participating countries to agree to achieve their emissions targets at any cost. Such an approach is not only very consistent with the UN Framework Convention on Climate Change, it is likely to be more viable than the current framework being negotiated under the Kyoto Protocol. China is a pivotal country in the global debate. The more its concerns can be taken into account in the design of a global post-Kyoto system, the more likely it is that the world will begin to take effective action on climate change.

We finish by emphasising the importance of combining a market-based carbon dioxide reduction mechanism with an ambitious program to accelerate the development of green technology. Such a program would probably have a higher chance of success if some important parts of it were based on interna- 
tional collaboration. For example, since China is building a coal-fired power plant each week, there is considerable opportunity to make some of those plants prototypes that could be used to test the scaling up of experimental technologies such as carbon capture and sequestration. On its own, China would hesitate to incur the costs of such experiments because others could quickly learn any useful findings. ${ }^{24}$ Clearly, international scientific cooperation paid for by the international community could hasten the progress of a range of new technologies.

\section{Notes}

1 The Japanese growth experience since 1870 clearly suggests that the income disparity between China and Western Europe is not independent of Chinese economic policies. In 1870, the average Japanese income was 37 per cent of that of the average Western European income, but after a century of policy-induced convergence of economic institutions in Japan with those in Western Europe and the United States, average Japanese income in 1973 was equal to average income in Western Europe. The growth experiences of South Korea and Taiwan since the early 1960s confirmed that catching-up growth was not unique to Japan.

2 Unless otherwise specified, all dollar figures refer to 1990 dollars.

3 At these growth rates, GDP per capita in 2100 would be $\$ 84,400$ in Western Europe and $\$ 92,800$ in China; and GDP per capita in 2150 would be $\$ 177,700$ in Western Europe and $\$ 192,100$ in India.

4 Possibly the most authoritative recent statement of this position is IPCC (2007).

5 The first four effects are from page 6 , and the fifth is from page 9. On the last effect, the IPPC added that 'while the effects of observed ocean acidification on the marine biosphere are as yet undocumented, the progressive acidification of oceans is expected to have negative impacts on marine shell-forming organisms (eg. corals) and their dependent species'.

6 'As global average temperature increase exceeds about $3.5^{\circ} \mathrm{C}$, model projections suggest significant extinctions (40 to $70 \%$ of species assessed) around the globe' (IPPC 2007:13-14).

7 The tipping point is defined as when the melting of the Greenland ice-cap becomes irreversible.

8 Raupach is quoted as saying

... if we manage to bring $\mathrm{CO}_{2}$ to equilibrium at $450 \mathrm{ppm}$, we would be looking at a temperature rise of 1 to 1.5 degrees above pre-industrial levels, some changes to rainfall patterns, some melting of the Arctic, significant acidification of the oceans through $\mathrm{CO}_{2}$ rise and so forth. But these are issues which would not cause widespread devastation...If we reach $550 \mathrm{ppm}$, we're getting into 2 to 2.5 degree temperature rise and the amount of climate damage that we would be looking at will in some cases... probably involve crossing thresholds that we can't recover from. If we keep on the present growth projectory then we get there by about 2046 (cited in Beer 2007).

9 The increment was $2.08 \mathrm{ppm}$ in 2002 and $2.54 \mathrm{ppm}$ in 2003; see Kirby (2004). The concentration of atmospheric carbon dioxide is taken to be 380 ppm in 2008. 
10 Gulledge (2008:52) has described the proposition that 'future climate change will be smooth and gradual' as a myth: 'The history of climate reveals that climate change occurs in fits and starts, with abrupt and sometimes dramatic changes rather than gradually over time.' Figure 3-1 in Gulledge (2008) makes this point dramatically in the time profile of the number of storms of tropical hurricane force in the North Atlantic in the period 1930-2007.

11 Gulledge (2008:56) points out that

...the models used to project future warnings either omit or do not account for uncertainty in potentially positive feedbacks that could amplify warming (for example, release of greenhouse gases from thawing permafrost, reduced ocean and terrestrial $\mathrm{CO}_{2}$ removal from the atmosphere), and there is some evidence that such feedbacks may already be occurring in response to the present warming trend.

12 Table 9.2 reports that the United States and China accounted for 35.2 per cent of global carbon dioxide emissions in 2004, and would account for 39.1 per cent in 2010.

13 Strictly speaking, the word 'country' is too narrow. The permits would be valid only within the political jurisdiction of issue. If the relevant jurisdiction is multinational-the European Union, for example-permits could be traded between countries within the broader jurisdiction.

14 This approach is known as a downstream policy because it applies to fuel users. It would also be possible to apply the policy upstream by imposing limits on the carbon embodied in fuels when they are produced-for example, at the mine mouth or well-head.

15 The negotiations, of course, would not be trivial: getting agreement on the annual price would require considerable diplomacy. It is interesting to note that a treaty of this form has a strong built-in incentive for countries to participate in the initial negotiations. Countries that participate will have a role in setting the annual price while those who remain on the sidelines will not. We are indebted to Jonathan Pershing for pointing this out.

16 Countries have different degrees of concern about climate change and different abilities to implement climate policies. A coordinated system of hybrid policies provides participants with the ability to tailor the policy to their own circumstances.

17 A government might prefer a carbon tax if it lacks the institutional and administrative mechanisms needed to operate a permit market.

18 In passing, it is worth noting that anti-competitive behaviour by the incumbents, while unlikely, would have an environmental benefit: it would reduce overall carbon emissions.

19 In contrast, a conventional international permit system could be particularly difficult to enforce because of the links it creates between countries. Restricting sales of permits by non-complying countries, as would be required under the Kyoto Protocol, would harm the interests of compliant countries by raising permit prices. The international links between permit markets therefore provide a strong incentive against enforcement of the agreement.

20 Although long-term permit owners would welcome an increase in the annual price, there is little risk that they would be able to drive prices up on their own. Given that other energy users provide countervailing pressure to keep energy prices low, it is hard to imagine that permit owners would be able to push a government into adopting an inefficiently high price and excessively stringent emissions policy.

21 The exact details of the target are not central to this paper because we will be comparing alternative policies for reaching a single set of targets; however, more rapid cuts in emissions would clearly give different results to those presented here. 
22 The excessive amount of long-term permits in the first few years of this policy option means that the global emissions of carbon dioxide in the third policy option exceed the amount of global carbon dioxide emissions in the first and second policy options (whose emissions equal each other's). It is interesting that if China were given an excessive amount of carbon credits in the second policy option, its emissions path and GDP path would still be the same as that shown in Figures 9.7 and 9.8 as long as the extra amount of carbon credits given to China was small and hence had no effect on the world price of carbon credits. As production in China is guided by the world price of carbon credits, it would remain unchanged, and China would just sell off the extra carbon credits and cause the global emissions to be larger than under the first policy option (domestic carbon tax) and the original second policy option (international cap and trade) where the allocated carbon credits were binding from the beginning.

23 A difference arises because the transfer of income across countries with different spending patterns can change carbon dioxide emissions and therefore the price required for an equivalent global target path.

24 This dilemma exists in other forms as well, illustrated by the recent decision of the Virginian regulator of utilities in the United States

...to turn down an application by the Appalachian Power Company to build a plant

that would have captured 90 per cent of its carbon and deposited it nearly two miles

underground, at a well that it dug in 2003. The applicant's parent was American

Electric Power, one of the nation's largest coal users, and perhaps the most

technically able. But the company is a regulated utility and spends money only when

it can be reimbursed (cited in Wald 2008).

The Virginia commission said that it was 'neither reasonable nor prudent' for the company to build the plant, and the risks for ratepayers were too great, because costs were uncertain, perhaps double that of a standard coal plant. And in a Catch-22 that plagues the whole effort, the commission said A.E.P. should not build a commercial-scale plant because no one had demonstrated the technology on a commercial scale (Wald 2008).

25 Full details of the model, including a list of equations and parameters, can be found online at www.gcubed.com

26 These issues include: Reaganomics in the 1980s, German unification in the early 1990s, fiscal consolidation in Europe in the mid 1990s, the formation of the North American Free Trade Agreement (NAFTA), the East Asian financial crisis and the productivity boom in the United States.

\section{References}

Bagnoli, P., McKibbin, W. and Wilcoxen, P., 1996. 'Future projections and structural change', in N. Nakicenovic, W. Nordhaus, R. Richels and F. Toth (eds), Climate Change: integrating economics and policy, CP 96-1, International Institute for Applied Systems Analysis, Vienna:181-206.

Beer, S., 2007. 'Atmospheric $\mathrm{CO}_{2}$ to reach first danger level by 2028: new research', 22 May 2007. Available from http://www.itwire.com/content/ view/12347/1066. 
Energy Information Agency (EIA), 2002. International Energy Outlook, Department of Energy, Washington, DC.

- - 2007. International Energy Outlook, Department of Energy, Washington, DC. - - , various years. International Energy Outlook, Department of Energy, Washington, DC.

Garnaut, R., Howes, S., Jotzo, F. and Sheehan, P., 2008. Emissions in the platinum age: the implications of rapid development for climate change mitigation, Paper presented at a seminar at The Australian National University, Canberra.

gcubed.com. Available at http://www.gcubed.com

Gulledge, J., 2008. 'Three plausible scenarios of climate change', in K. Campbell (ed.), Climatic Cataclysm: the foreign policy and national security implications of climate change, Brookings Institution Press, Washington, DC.

Intergovernmental Panel on Climate Change (IPPC), 2007. Climate Change 2007: synthesis report, Cambridge University Press, Cambridge.

International Monetary Fund (IMF), 2008. World Economic Outlook, April, International Monetary Fund, Washington, DC.

Kaya, Y., 1990. Impact of carbon dioxide emission control on GNP growth: interpretation of proposed scenarios, Paper presented to the Intergovernmental Panel on Climate Change Energy and Industry Subgroup, Response Strategies Working Group, Paris.

Kirby, A., 2004. 'Carbon "reaching danger levels"', BBC News Online, 13 October. Available from http://news.bbc.co.uk/1/hi/sci/tech/3737160.stm

Kuznets, S., 1966. Modern Economic Growth: rate, structure, and spread, Yale University Press, New Haven.

Maddison, A., 2001. The World Economy: a millennial perspective, Organisation for Economic Cooperation and Development, Paris.

_—, 2007. 'horizontal-file_03-2007.xls', File downloaded from Internet. Available from www.ggdc.net/maddison/Historical_Statistics/horizontal-file_03-2007.xls McKibbin, W., Pearce, D. and Stegman, A., 2007. 'Long term projections of carbon emissions', International Journal of Forecasting, 23:637-53.

McKibbin, W. and Wilcoxen, P., 1998. 'The theoretical and empirical structure of the G-cubed model', Economic Modelling, 16(1):123-48.

-_, 2002a. Climate Change Policy After Kyoto: a blueprint for a realistic approach, The Brookings Institution, Washington, DC.

- - 2002b. 'The role of economics in climate change policy', Journal of Economic Perspectives, 16(2):107-30.

- - 2007. 'A credible foundation for long term international cooperation on climate change', in J. Aldy and R. Stavins (eds), Architectures for Agreement: 
addressing global climate change in the post-Kyoto world, Cambridge University Press, Cambridge:185-208.

_- 2008. Building on Kyoto: towards a realistic climate change agreement, Paper presented to the Brookings Institution High-Level Workshop on Climate Change, Tokyo, 30 May .

Nordhaus, W., 2008. 'Economic analyses of the Kyoto Protocol: is there life after Kyoto?', in E. Zedillo (ed.), Global Warming: looking beyond Kyoto, Brookings Institution Press, Washington, DC.

Obstfeld, M. and Rogoff, K., 1996. Foundations of International Macroeconomics, MIT Press, Cambridge, Mass.

Wald, M.L., 2008. 'Running in circles over carbon', New York Times, 8 June.

\section{Appendix}

\section{The G-cubed model}

The G-cubed model is an inter-temporal general-equilibrium model of the global economy. The theoretical structure is outlined in McKibbin and Wilcoxen (1998). ${ }^{25}$ A number of studies show that the G-cubed modelling approach has been useful in assessing a range of issues across a number of countries since the mid $1980 \mathrm{~s} .{ }^{26}$ Some of the principal features of the model are as follows.

- The model is based on explicit inter-temporal optimisation by the agents (consumers and firms) in each economy (Obstfeld and Rogoff 1996). In contrast with static computable general equilibrium (CGE) models, in the $G$-cubed model, time and dynamics are of fundamental importance. The G-cubed model is known as a dynamic stochastic general equilibrium (DSGE) model in the macroeconomics literature and as a dynamic intertemporal general equilibrium (DIGE) model in the CGE literature.

- In order to track the macro-time series, the behaviour of agents is modified to allow for short-run deviations from optimal behaviour due either to myopia or to restrictions on the ability of households and firms to borrow at the risk-free bond rate on government debt. For households and firms, deviations from inter-temporal optimising behaviour take the form of rules of thumb, which are consistent with an optimising agent that does not update predictions based on new information about future events. These rules of thumb are chosen to generate the same steadystate behaviour as optimising agents so that in the long run there is only a single inter-temporal optimising equilibrium of the model. In the short run, real behaviour is assumed to be a weighted average of the optimising and the rule-of-thumb assumptions. Aggregate consumption is therefore 
a weighted average of consumption based on wealth (current asset valuation and expected future after-tax labour income) and consumption based on current disposable income. Similarly, aggregate investment is a weighted average of investment based on Tobin's 'Q' (a market valuation of the expected future change in the marginal product of capital relative to the cost) and investment based on a backward looking version of ' $Q$ '.

- There is an explicit treatment of the holding of financial assets, including money. Money is introduced into the model through a restriction that households require money to purchase goods.

- The model also allows for short-run nominal wage rigidity (by different degrees in different countries) and therefore allows for significant periods of unemployment depending on the labour-market institutions in each country. This assumption, when taken with the explicit role for money, is what gives the model its 'macroeconomic' characteristics (here again, the model's assumptions differ from the standard market-clearing assumption in most CGE models).

- The model distinguishes between the stickiness of physical capital within sectors and within countries and the flexibility of financial capital, which immediately flows to where expected returns are highest. This important distinction leads to a critical difference between the quantity of physical capital that is available at any time to produce goods and services, and the valuation of that capital as a result of decisions about the allocation of financial capital.

As a result of this structure, the G-cubed model contains rich dynamic behaviour, driven on the one hand by asset accumulation and, on the other, by wage adjustment to a neoclassical steady state. It embodies a wide range of assumptions about individual behaviour and empirical regularities in a general-equilibrium framework. The interdependencies are solved using a computer algorithm that solves for the rational-expectations equilibrium of the global economy. It is important to stress that the term 'general equilibrium' is used to signify that as many interactions as possible are captured, not that all economies are in a full market-clearing equilibrium at each point in time. Although it is assumed that market forces eventually drive the world economy to a neoclassical steady-state growth equilibrium, unemployment does emerge for long periods due to wage stickiness-to an extent that differs between countries due to differences in labour-market institutions. 


\title{
Table A9.1 Overview of the G-cubed model (version 80J)
}

\author{
Regions \\ United States \\ Japan \\ Australia \\ Europe \\ Rest of the OECD \\ China \\ India \\ Oil-exporting developing countries \\ Easter Europe and the former Soviet Union \\ Other developing countries \\ Sectors \\ Energy: \\ Electric utilities \\ Gas utilities \\ Petroleum refining \\ Coal-mining \\ Crude oil and gas extraction \\ Non-Energy: \\ Mining \\ Agriculture, fishing and hunting \\ Forestry/wood products \\ Durable manufacturing \\ Non-durable manufacturing \\ Transportation \\ Services \\ Capital-producing sector
}

